\title{
Dimensions of coping and anxiety symptoms in a community sample of young children
}

Dr Katie Quy

Department of Social Science, UCL Institute of Education, London, United Kingdom

Thomas Coram Research Unit, Department of Social Science, UCL Institute of

Education, 27-28 Woburn Square, London WC1H 0AA

k.quy@ucl.ac.uk

Dr Jennifer Gibb

National Children's Bureau, London, United Kingdom

Dr Louise Neil

Division of Psychology and Language Sciences, UCL, London, United Kingdom

Charlie Owen

Department of Social Science, UCL Institute of Education, London, United Kingdom

Professor Marjorie Smith

Department of Social Science, UCL Institute of Education, London, United Kingdom 


\title{
Dimensions of coping and anxiety symptoms in a community sample of young children
}

\begin{abstract}
Coping style plays an important role in children's wellbeing. This paper describes the patterns of associations between children's self-reported coping styles and symptoms of anxiety in order to determine whether particular dimensions are associated with better adjustment. Participants were 2566 children (1268 girls, 1298 boys) aged seven to eleven years attending 15 schools in the South East of England. Results showed that aspects of coping were differentially associated with children's self-reported anxiety. Patterns of association also varied by age and gender. Dimensions of coping were shown to form distinct adaptive and maladaptive coping styles which were also differentially associated with anxiety. Analysis of these styles indicated that it is the absence of maladaptive coping strategies, rather than the presence of adaptive strategies, that is significant in emotional wellbeing. These findings suggest that interventions designed to reduce or extinguish maladaptive coping styles may be of particular benefit in facilitating emotional wellbeing.
\end{abstract}

\section{Keywords}

Coping; anxiety; wellbeing; emotion regulation; child; multidimensional; adaptive; intervention

\section{Introduction}

Anxiety is one of the most common forms of psychological distress in childhood. While estimated prevalence of clinical anxiety disorder ranges from 4\% (Meltzer, 
Gatward, Goodman, \& Ford, 2004) to as high as 17\% (Degnan, Almas, \& Fox, 2010), subclinical levels of anxiety symptoms are considerably more pervasive, with around one third of children estimated to experience problems with anxiety which cause significant impairment but do not meet diagnostic criteria (Chavira, Stein, Bailey, \& Stein, 2004). The different ways in which we navigate and respond to challenging or stressful circumstances can have significant implications for our psychological health (Zeidner \& Endler, 1996), and understanding how children attempt to cope with challenges and stressors in daily life is likely to be key to supporting their wellbeing and development, and to reducing symptoms of anxiety.

A number of studies have found associations between particular coping patterns and measures of psychological adjustment in children. Compas and colleagues undertook a review of 63 child and adolescent coping studies carried out since 1988 (Compas, Connor-Smith, Saltzman, Thomsen, \& Wadsworth, 2001). This showed 'engagement coping', including problem solving, emotional expression and support seeking, to be consistently associated with fewer internalising symptoms, while 'disengagement coping', encompassing problem avoidance, cognitive avoidance and social withdrawal, and 'emotion-focused coping', including denial, wishful thinking and emotional expression, were consistently associated with higher levels of internalising symptoms. As noted by the authors, however, the broad categorisations of coping adopted in the review, as well as in many of the studies discussed, provide limited insight into the unique relationships between adjustment and the individual strategies making up a coping style profile. These categorisations tend to be unidimensional, while coping is increasingly being conceptualised as a multidimensional construct (Quy, Gibb, Neil, \& Smith, in press; Skinner, Pitzer, \& Steele, 2013; Zimmer-Gembeck \& Skinner, 2011). 
Some studies have attempted to take a more nuanced approach to assessing the relationship between coping and adjustment in children by examining the relationship between more specific, individual, dimensions of coping and wellbeing rather than broader classifications. For example, the use of reappraisal and positive interpretation has been demonstrated to be associated with positive psychological adjustment in samples of children aged 12-16 years (Garnefski, Legerstee, Kraaij, Van den Kommer, \& Teerds, 2002), 9-11 years (Garnefski, Rieffe, Jellesma, Terwogt, \& Kraaij, 2007) and 7-18 years (Thomsen et al., 2002), while ruminative tendencies have been shown to predict anxiety in children aged 12-16 (Garnefski et al., 2007) and depression in children and adolescents aged 8-13 years (Wright, Banerjee, Hoek, Rieffe, \& Novin, 2010). Similarly, involuntary engagement (e.g., responses characterised by rumination and physiological reactivity,) has been shown to be associated with higher levels of anxiety and somatic symptoms, and depression in 7-18 year olds (Thomsen et al., 2002), while constructive problem solving has been shown to be positively associated with emotional well-being in children aged 9-13 (Ayers, Sandler, West, \& Roosa, 1996), 812 (Eisenberg et al., 1996), and 7-18 years (Thomsen et al., 2002).

Indicators of emotion regulation and management have also been demonstrated to be associated with various types of children's internalising symptoms in several studies. For example, in a sample of children and young adolescents aged 8-12 years, Eisenberg et al. (1996) found that attentional regulation was related to negative emotionality, a dimension of temperament characterised by higher levels of irritability, negative arousal and sadness (Derryberry \& Rothbart, 1988). Similarly, emotional awareness has been shown to play a significant role in successful emotion regulation, and the ability to recognise, and discriminate between, emotions has been associated with children's wellbeing (Gilleland, Suveg, Jacob, \& Thomassin, 2009; Rieffe, 
Oosterveld, Miers, Meerum Terwogt, \& Ly, 2008). Associations have also been identified between children's use of catastrophising (e.g. feeling problems are unstoppable or unmanageable) and self-isolation or trying to avoid others (Kaminsky, Robertson, \& Dewey, 2006; Walker, Smith, Garber, \& Van Slyke, 1997), and inaction and behavioural disengagement (Thomsen et al., 2002), and adjustment, including higher levels of somatic symptoms and anxiety, and depressive symptoms. Finally, denial and cognitive avoidance (trying to ignore or not think about sources of stress) have been found to be associated with depressive symptoms in 9-15 year olds at risk for depression (Dunbar et al., 2013). These findings indicate that a multidimensional assessment of coping would be particularly valuable in predicting children's wellbeing. In particular, they suggest that strategies such as rumination, self-blame and catastrophising are likely to be associated with higher levels of internalising symptoms, while strategies such as trying to generate solutions, and positive reappraisal, or thinking about situations in a more positive light, are likely to be associated with lower levels of internalising symptoms.

The research findings described above provide support for the claim that aspects of coping may be differentially associated with children's wellbeing. This suggests that 'disaggregating' coping into distinct dimensions might be a useful way to explore the relationship between individual coping strategies and children's emotional adjustment. Examining these dimensions at an individual level may then provide a foundation for determining whether and how they may work together to function as composite 'styles' of coping.

The aim of the current study, which was conducted in a community sample of children aged between seven and eleven years, was to explore the relationship between children's perspectives on their own coping responses assessed as a multidimensional 
construct and their self-reported symptoms of anxiety. This was in order to determine whether particular individual dimensions were associated with better (or worse) adjustment for children in terms of symptoms of anxiety. A secondary aim was to explore whether associations between coping and wellbeing varied by age or gender, in order to identify whether these factors play a significant role. Finally, it was proposed to explore whether individual strategies may be combined into overarching 'styles' of coping based on their relationship with emotional wellbeing.

\section{Methodology}

\section{Sample population and participants}

Participants were 2566 children (1268 girls and 1298 boys) aged seven to eleven years (key stage 2) attending 15 schools across three different Local Education Authorities (LEAs) in the South East of England (two in London and one north of London). The criteria for selection of LEAs and schools within them aimed to ensure a reasonably diverse and representative sample in order to facilitate inference from findings to the wider population. Selection criteria were drawn from Local Authoritylevel data relating to eligibility for Free School Meals, proportion of non-English speakers, and demographic information, obtained from the (then) Department of Children, Schools and Families. Table 1 presents comparative demographic data on each of the areas and the schools selected within them:

\section{<Insert Table 1 about here>}

\section{Measures}

Questionnaire packs were developed to assess symptomatology and coping dimensions. Symptomatology was assessed using the Spence Children's Anxiety Scale 
(SCAS: Spence, 1998), an Australian scale designed to measure the severity of anxiety symptoms in children. The scale assesses anxiety across six dimensions: generalized anxiety, panic/agoraphobia, social phobia, separation anxiety, obsessive compulsive disorder and physical injury fears, selected to reflect the dimensions of anxiety disorder as set out in the Diagnostic and Statistical Manual (DSM-IV). Internal consistency and test-retest reliability of the scale was demonstrated to be high $(\alpha=0.9)$. Convergent validity was investigated between the SCAS and the Revised Children's Manifest Anxiety Scale (RCMAS: Reynolds and Richmond, 1978), and results indicated a strong, positive correlation $(\mathrm{r}=0.7, \mathrm{~N}=218, \mathrm{p}<0.001)$. Discriminant validity was assessed by investigating correlations between scores for the SCAS and child-report on the Children's Depression Inventory (CDI: Kovacs, 1981). The relationship between the SCAS and the CDI was found to be significantly weaker than the relationship between the SCAS and the RCMAS $(\mathrm{Z}=4.77, \mathrm{~N}=218, \mathrm{p}<0.001)$.

The SCAS scale comprises 44 items: 38 assessing each of the six anxiety dimensions, and six additional 'positive' items, not included in the total score, designed to minimise response bias and dilute the negativity of the measure. Children were asked to rate how much they had experienced each 'symptom' over the previous two weeks. Responses were scored on a four-point scale from 0-3 (not at all, a little, quite a bit, a lot) ${ }^{1}$. Possible scores range from $0-114$, with higher scores indicating greater anxiety.

Coping was assessed using the Profile of Coping Dimensions in Children (PCDC: Quy et al., in press), a self-report measure designed to assess children's coping

\footnotetext{
${ }^{1}$ The timescale and anglicised responses were introduced to align the anxiety measure with other instruments and ensure ease of use for children. The amended versions were piloted to ensure the changes did not impact significantly on results.
} 
style. Items were derived from a review of research findings and items from existing measures, to increase the likelihood that they would be valid and reliable measures of coping. Key dimensions of coping were identified from the relevant literature, and then a pool of items to assess these dimensions was created or adapted from existing measures (see Table 2. for items and the corresponding coping constructs to be assessed). These items were then reviewed for age appropriateness and content validity by a team of four researchers with relevant knowledge of the topic, and the scale was piloted in three schools. In order to ensure the measure was as simple as possible, eleven items which were deemed to best capture the dimensions of coping highlighted in the literature were included. The measure asked children to indicate whether or not they endorsed each of eleven coping strategies designed to assess dimensions of coping. The measure was prefaced with the statement, 'Everyone feels different when they are worried or upset. Please look at the sentences below, and tell us if they are true for you', with possible response options of 'yes' or 'no'. To help children frame their responses, statements were then prefaced with "When I am worried or upset, I..." Concurrent validity of the measure was demonstrated against bespoke measures of stress and sources of happiness and a Cohen's kappa statistic (Cohen, 1960) calculated for each item in the measure over a three month interval, demonstrated reasonable stability (Quy et al., in press).

\section{<Insert Table 2 about here>}

\section{Procedure}

Within the selected schools, all children in the appropriate age group (key stage 2 classes) were invited to take part. All parents/carers had previously been sent a letter informing them of the research and allowing them to opt their children out if they 
wished. Questionnaires were administered in class groups in the presence of the class teacher. At the beginning of the session a researcher explained the research, and what was required of the children, and asked them if they would be willing to participate. Researchers administered questionnaires made up of measures designed to assess recent symptoms of anxiety and coping dimensions. Where available, and particularly in younger groups, classroom assistants were also engaged to facilitate the process. The researcher explained the administration process and ran through several examples to ensure children understood how to complete the measure correctly. The researcher was available throughout the session to answer any queries and help with comprehension if necessary. In the younger class groups (Years 3 and 4) a researcher read each item aloud to the class as a group. Children in the older class groups (Years 5 and 6) were asked to complete the measure independently, but additional help was provided where necessary. At the end of the session children were thanked for their help, and invited to comment and ask questions, and each class was awarded a 'certificate of achievement' in recognition of their contribution to the research.

Ethical consent for this work was sought and obtained from the Faculty Research Ethics Committee.

\section{Results}

To examine relationships between individual coping dimensions and emotional wellbeing, one-way ANCOVAs were used to explore the association between coping dimensions and children's anxiety, while taking into account the effect of age and gender and their interaction with coping. While these data were not strictly parametric, a review of alternative procedures suggested that ANCOVA was the most robust and suitable statistic for these data, given that the violation of assumptions was relatively 
minor (Olejnik \& Algina, 1984). Since anxiety symptoms were found to vary by age and gender, these variables were included in analyses in order to determine their impact on any relationship between coping dimensions and children's anxiety levels. In order to address the issue of multiple comparisons (for each of the eleven coping dimensions), a Bonferroni adjustment was applied to correct the alpha level as follows: $0.05 / 11=$ 0.005 .

Table 3 shows the association between coping dimensions and levels of selfreported anxiety.

\section{<Insert Table 3 about here>}

\section{Coping dimensions associated with lower levels of self-reported anxiety}

Children who endorsed the items 'I can usually do something to make the situation better' and (to a lesser extent) 'I can see the good side of things', reported significantly lower levels of anxiety. Interaction effects indicated that the relationship between anxiety scores and endorsing these dimensions was slightly stronger for girls. A moderately robust relationship was observed between the item 'I can change how I feel' and lower anxiety scores. There were no significant interaction effects for age or gender for this item. Similarly, being able to regulate one's emotions ('I can calm myself down') was moderately strongly associated with lower levels of self-reported anxiety. A significant interaction effect indicated that this effect was stronger for older children. There was no significant interaction effect for gender.

\section{Coping dimensions associated with higher levels of self-reported anxiety}

Each of the items 'I find it hard to stop thinking about it' (rumination and preoccupation), 'There is nothing I can do about it' (behavioural (dis)engagement and 
catastrophizing), and 'Sometimes I don't know why I'm upset' (emotional awareness), demonstrated a moderate to large significant main effect associated with higher anxiety scores, even controlling for age and gender. The item 'Getting angry helps me to feel better' (proneness to responding with anger) was similarly associated with higher levels of self-reported anxiety, although the effect was small. There were no significant interaction effects for any of these dimensions, indicating that the impact of dimensions did not vary by age or gender

Endorsing the item 'I stay upset for several days' (perseveration of negative emotion) was also strongly associated with higher levels of anxiety. Interaction effects indicated that this effect was particularly strong for girls, but there was no association with age.

Trying not to think about problems (denial and cognitive avoidance) and trying to think about solutions (active and constructive coping) were not associated with any difference in anxiety scores after adjusting for age and gender.

To summarise, difficulties in managing negative thoughts and feelings were particularly associated with higher levels of anxiety. A problem-solving approach to difficulties, confidence in ability to manage situations and a positive outlook were related to lower levels of anxiety. Gender and age were relevant in several of these associations. While the ability to focus on positives and generate practical solutions were associated with better emotional adjustment particularly for girls, perseveration was particularly problematic. In terms of age, emotion regulation skills were more strongly associated with lower levels of symptoms for older children than for younger children. 
There were also some potentially interesting age trends emerging which did not reach statistical significance. There was a trend towards being able to see the good side of things being more strongly related to lower levels of anxiety for older children, while feeling helpless was slightly more strongly related to higher levels of anxiety for older children.

\section{Identifying coping 'styles'}

In order to determine whether individual coping dimensions could be usefully grouped together to capture an individual's 'style' of coping, the eleven items of the PCDC measure were subjected to principal components analysis. The Kaiser-MeyerOklin value was .77, exceeding the recommend value of .6 (Kaiser, 1970, 1974) and the Bartlett's test of sphericity (Bartlett, 1954) reached statistical significance, supporting the factorability of the correlation matrix.

Principal components analysis revealed the presence of three components with eigenvalues greater than 1, explaining $22.86 \%, 13.39 \%$ and $9.52 \%$ of the variance respectively. Inspection of the scree plot indicated a break after the second component, and based on Cattell's scree test (Cattell, 1966), it was decided to retain two components. This was further supported by the results of Parallel Analysis (Chang, Cheng, Allaire, Xie, \& McPherson, 2016; Horn, 1965), which showed only two components with eigenvalues exceeding the corresponding criterion values for a randomly generated data matrix of the same size (11 variables x 2556 cases )

As factors in the measure were expected to be correlated, a direct oblimin rotation was performed to enable interpretation of the two identified factors. The rotated solution revealed the presence of simple structure (Thurstone, 1947). A single item, 'Getting angry helps me to feel better' did not load substantially on either factor and was therefore excluded. The two component solution explained a total of 36.3 
percent of the variance ( $22.9 \%$ and $13.4 \%$ respectively). Component 1 was labelled 'Adaptive Coping Style' and component 2 was labelled 'Maladaptive Coping Style'. Table 4 shows the items comprising each proposed 'style'.

\section{<Insert Table 4 about here>}

Independent samples t tests were conducted in order to determine the relationship between maladaptive and adaptive coping styles. Children who scored high on the adaptive coping factor had significantly lower anxiety scores $(M=28.22$, $\mathrm{SD}=17.71)$ than those who scored low on this factor $(\mathrm{M}=33.74, \mathrm{SD}=20.18), t(1952.63)$ $=7.08, \mathrm{p}<.001, \mathrm{CI}=3.99-7.05, d=.3)$. Conversely, children who scored high on the maladaptive coping factor had significantly higher anxiety scores $(M=36.47, S D=19.14)$ than those who scored low on this factor $(\mathrm{M}=22.71, \mathrm{SD}=15.53), t(2546.99)=-20.04, \mathrm{p}$ $<.001, \mathrm{CI}=-15.10--12.41, d=.8)$.

\section{<Insert Table 5 about here>}

In order to explore whether children were likely to favour a particular multidimensional style, the sample was classified into four groups based on their use of coping styles: maladaptive copers (children scoring above the mean on maladaptive style, but below the mean on adaptive style), adaptive copers (children scoring above the mean on adaptive style, but below the mean on maladaptive style), versatile copers (children who scored above the mean on both styles) and non-responsive copers (children who scored below the mean on both styles). Table 5 shows the frequency of each style within the sample. The most common style was adaptive coping (endorsing high levels of adaptive dimensions and low levels of maladaptive items, and versatile coping (endorsing both maladaptive and adaptive dimensions). The least common style was non-responsive. Girls were significantly more likely to demonstrate both maladaptive and versatile coping styles, while boys were significantly more likely to 
endorse both an adaptive style and a non-responsive style $\left(\chi^{2}(3, \mathrm{~N}=2556)=87.27\right.$, $\mathrm{p}$ $.001)$. The effect size was small to medium, indicating slight to moderate differences $(\phi$ $=.2)$.

ANCOVAs were used to explore the association between these composite coping styles and children's anxiety. Age and gender were again included in analyses as covariates in order to determine their impact on any relationship between coping styles and children's anxiety levels. Analyses revealed that there was a significant difference between the type of coping style used by children and their levels of anxiety $[F(3,2539)=124.96, p<.001]$ The effect size, calculated using eta squared was 0.13 , indicating a large effect. There were no significant interaction effects for age or gender for these relationships, indicating that these factors did not significantly impact the relationship between coping styles and outcomes. Children who endorsed a maladaptive style had the highest levels of anxiety $(\mathrm{M}=39.85, \mathrm{SD}=19.64)$, followed by children endorsing a versatile coping style $(\mathrm{M}=33.57, \mathrm{SD}=18.23)$. Children who endorsed an adaptive style $(\mathrm{M}=22.92, \mathrm{SD}=15.47)$ or a non-responsive style $(\mathrm{M}=$ 22.25, $\mathrm{SD}=15.69)$ reported the lowest levels of anxiety. Post hoc comparisons indicated that differences between groups were significant for all but the adaptive and non-responsive groups.

\section{<Insert Table 6 about here>}

In order to examine the nature of these differences between coping styles, an ANCOVA was used to examine whether there was an interaction between maladaptive and adaptive coping styles (see Table 6). Both maladaptive coping and adaptive coping styles exerted a significant main effect on children's anxiety scores. Effect sizes calculated using partial eta squared indicated a large effect for maladaptive coping, and a small effect for adaptive coping. The relationship between maladaptive coping and 
anxiety was particularly strong for girls. This analysis also showed a small but significant interaction effect between coping styles. For children high on maladaptive coping, anxiety scores were lower for those who did not also endorse adaptive coping (i.e. maladaptive style). However, for children who scored low on maladaptive coping, endorsing an adaptive coping style was not related to anxiety (see Figure 1).

\section{<Insert Figure 1 about here>}

\section{Discussion}

This study offers significant new findings relating to the association between children's coping and emotional wellbeing. Of particular importance in generating these findings is the fact that this study considers coping as a multidimensional construct, comprising distinct facets or dimensions. This approach is useful both in allowing for associations between specific coping dimensions and children's wellbeing to be revealed, but also enabling the more comprehensive profile of children's coping to be captured.

When considering the results presented here, it is important to acknowledge that these findings do not establish a causal direction for observed relationships between coping and children's emotional adjustment. While it may be that adopting particular coping strategies, or combinations thereof, may result in higher (or lower) levels of anxiety, it may be the case that more (or less) anxious children tend to develop particular coping styles. It is also plausible that both coping style and symptoms of anxiety are functions of a third variable, such as, for example, biological influences or parenting style, or the level of stress experienced.

Findings showed that specific strategies were differentially associated with children's emotional wellbeing. While, as noted previously (Quy et al., in press) 
preoccupation and perseveration were relatively uncommon coping responses, they were most strongly associated with higher levels of symptoms. The findings relating to perseveration (ability - or not - to change how one feels, getting angry, and staying upset for several days) suggest that endorsing coping strategies associated with poorer management of emotion may be particularly problematic in terms of internalising symptoms. This corresponds with the literature on emotion regulation, in which emotion regulation has been identified as a process distinct from emotion (e.g. Delgado, Nearing, LeDoux, \& Phelps, 2008), with a significant role in diminishment or augmentation of the experience of emotion, including anxiety (Cisler, Olatunji, Feldner, \& Forsyth, 2010; Gross, 1998). The findings relating to preoccupation (for example, being unable to stop thinking about upsets) follow similar patterns. This bears out findings in the literature on repetitive thoughts, which have demonstrated that rumination is related to increased negative affect (Segerstrom, Tsao, Alden, \& Craske, 2000) and negative cognitions (Lyubomirsky \& Nolen-Hoeksema, 1995). These findings suggest that strategies associated with preoccupation, rumination and perseveration may warrant particular attention when considering potential pathways to anxiety for children.

Endorsing a problem-solving approach to difficulties, confidence in ability to manage situations and a positive outlook were associated with lower levels of anxiety. These findings provide support for the concept of a constructive approach to upsets, and may be best understood using the model of 'social problem solving' in adults, set forth by D'Zurilla and colleagues (D'Zurilla \& Goldfried, 1971; D'Zurilla \& Nezu, 1982, 1999). In this model, social problem solving is conceptualised as a construct made up of two elements, problem solving proper, and 'problem orientation', the process through which an individual typically approaches perceived problems. According to this model, 
this process is governed by comparatively stable 'cognitive-emotional schemas' which determine how an individual perceives problems and their ability to manage them (Belzer, D’Zurilla, \& Maydeu-Olivares, 2002). Deficits in problem orientation (i.e. lack of confidence in one's problem solving abilities, and perceiving problems as more difficult to overcome) has been linked with increased worry and anxiety in adults (Ladouceur et al., 1999). These findings indicate that this relationship may emerge relatively early in childhood.

Findings also demonstrated differences between broader composite styles of coping and children's wellbeing. Factor analytic techniques were used to identify two underlying factors: 'adaptive' and 'maladaptive' coping styles. As would be expected, scoring highly on the maladaptive style was associated with higher anxiety, while scoring highly on the adaptive dimension was associated with lower levels of selfreported anxiety, albeit to a lesser extent. Overall, children who coped in a maladaptive style were the most anxious, but those who were the least anxious were equally likely use primarily adaptive or non-responsive styles of coping. This finding suggests that it is the absence of maladaptive coping strategies, rather than the presence of adaptive strategies, that is significant in emotional wellbeing.

Taken together, these findings suggest that some strategies may be more (or less) adaptive in terms of children's wellbeing. While, as noted previously, the crosssectional nature of the data presented here does not allow us to speculate in terms of causality or directionality, other studies offer some evidence of indicative directionality. For example, Barrett and colleagues (Barrett, Farrell, Ollendick, \& Dadds, 2006; Barrett, Lock, \& Farrell, 2005; Barrett \& Turner, 2001) have demonstrated that programmes such as FRIENDS, a cognitive-behavioural intervention designed to promote the development of coping skills through relaxation, cognitive restructuring 
and attentional training, can significantly reduce children's anxiety symptoms and prevent the development of anxiety disorder, while more recently Creswell and colleagues have shown the effectiveness of similar CBT based interventions in reducing anxiety (Creswell et al., 2017). These findings provide some evidence to support the notion that coping styles may impact on emotional wellbeing and adjustment.

The current study has demonstrated that individual factors, particularly age and gender, may function as moderators of the relationship between coping dimensions and emotional wellbeing. In terms of age, emotion regulation skills were more strongly associated with lower levels of symptoms for older children than for younger children. While existing research is primarily concerned with emotion regulation in older children (aged 11 years+) and adults, there is some indication in the literature that emotion regulation strategies become more adaptive with age (McRae et al., 2012; Zimmermann \& Iwanski, 2014). Anxiety symptoms, on the other hand, are commonly reported to decrease with age from childhood to adolescence, at least in community populations (Cohen et al., 1993; Spence, Barrett, \& Turner, 2003) although the opposite trend has been reported in clinical populations (Degnan et al., 2010). This decrease could support the suggestion that, in typical circumstances, older children become less anxious because they may be developmentally more capable of emotion regulation.

Data presented here indicate that gender was also a significant factor in the relationship between particular dimensions of coping and symptoms of anxiety. While the ability to see the good side of things and generate practical solutions were particularly associated with lower levels of anxiety for girls, perseveration was particularly problematic for this group. These findings reflect similar patterns found in the adult literature which suggest that gender may moderate the relationship between coping styles and emotional adjustment (Garnefski, Teerds, Kraaij, Legerstee, \& van 
den Kommer, 2004; Kelly, Tyrka, Price, \& Carpenter, 2008) and suggest that they may be applicable considerably earlier in development. It may be that the capacity to employ strategies aimed at generating constructive solutions, and the tendency to 'look on the bright side' are protective factors for girls, while strategies which may be associated with poorer emotional regulation constitute a particular risk for this group. These findings may be particularly significant in the context of early intervention for children, given that gender-related patterns of differences in mental health problems tend to emerge in early adolescence (McLean \& Anderson, 2009; Nolen-Hoeksema \& Girgus, 1994), as do findings which suggest that coping intervention programmes may have differential impact for girls and boys (Frydenberg et al., 2004).

Overall, these findings suggest that significant associations exist between the coping strategies and styles children adopt, and their emotional wellbeing, assessed in this instance as self-reported symptoms of anxiety. While some strategies and styles were found to relate to lower levels of symptoms, others emerged as potentially maladaptive in terms of their association with emotional wellbeing. These relationships were further observed to vary as a function of gender and age. These findings offer significant scope to identify children potentially at risk of poorer emotional wellbeing, and to develop strategies to bolster children's capacity to manage day to day challenges by addressing use of maladaptive strategies. The presence (or absence) of maladaptive strategies emerged as the most significant factor in children's wellbeing, suggesting that while promoting 'adaptive coping' is a worthwhile and effective approach, focusing on the reduction or elimination of maladaptive coping strategies may be even more successful in facilitating emotional wellbeing. 


\section{Limitations and future directions}

While this study offers his study offers substantial evidence to support differential relationships between aspects of coping and emotional adjustment for children, some limitations must be acknowledged. The authors suggest there is scope for further development in four main areas. Firstly, while this study provides evidence of dimension specific associations with indicators of wellbeing, further exploration and refinement of the individual dimensions could offer significant scope for better understanding of these relationships. Specifically, development of the coping measure to expand its depth and scope by generating additional items to capture dimensions, and employing factor analytic techniques to determine underlying factors could provide additional weight and greater specificity to the evidence presented here.

Secondly, the relationships between coping and wellbeing established in this study are confined to children's self-reported anxiety. While obtaining children's perspectives on their own coping and wellbeing is key, further validating these by seeking additional perspectives, from, for example, parents or teachers could add weight to conclusions. Future studies might also benefit from the inclusion of additional measures of emotional and psychological health and wellbeing, such as depression, selfesteem and subjective wellbeing, in order to more fully understand the role of coping in children's development.

Thirdly, as noted above, while this study provides evidence to support differential associations between aspects of coping and children's wellbeing, interpretation, and particularly the potential to infer causal direction, is limited by the cross-sectional nature of the data. Future longitudinal work expanding these data to capture use and development of coping strategies, and emotional wellbeing over time 
would considerably enhance understanding of the nature, patterning and stability of these relationships. This developmental approach might also allow us to explore whether some of the patterns of association, and suggested moderating relationships, which did not reach statistical significance, are representative of emerging (or waning) trends not captured in the available data.

Finally, the relationships observed between particular coping strategies and dimensions, and indicators of wellbeing, warrant further examination with a view to informing intervention. These findings offer the opportunity to identify and target coping skills that may be less adaptive, and develop targeted intervention programmes to address potential deficits and support the development of more protective strategies. While effective interventions have been identified which have been successful in reducing anxiety, these can involve significant effort from children and families and are designed to build general coping skills. The current research offers the opportunity to identify specific deficits in coping skills and tailor intervention to individual children or groups.

\section{Conclusion}

The aim of this paper was to examine the nature and patterning of associations between self-reported coping dimensions and symptoms of anxiety in a community sample of children aged 7-11 years. It focuses on a non-clinical sample of children drawn from the wider community, and attempts to provide an understanding of the experience of managing day to day difficulties for ordinary children in everyday life. Aspects of coping were found to be differentially associated with children's selfreported anxiety symptoms, suggesting that particular strategies may be more or less adaptive in terms of emotional wellbeing. These data also highlight some potentially significant age and gender differences relating to the association between particular 
coping dimensions and self-reported symptomatology, suggesting that these relationships may, to a certain extent, be moderated by age and gender. As well as providing information on the potential role of particular coping dimensions in children's wellbeing, the findings generated using this multidimensional approach to coping suggest possibilities for more tailored interventions designed to address particular coping styles likely to be problematic as a function of characteristics of the individual.

\section{Acknowledgments}

This research was generously supported by Policy Research Programme in the Department of Health (project number 005/0134). The views expressed are not necessarily those of the Department.

Sincere thanks to the children who kindly agreed to participate in this study. Thanks also to their parents and carers, and to the schools we visited, for their support in data collection. 
Table 1. Demographic data relating to areas and schools

\begin{tabular}{lcc}
\hline & Deprivation Index rank & $\%$ Black and minority ethnic (BME) \\
\hline England \& Wales & & $11.3 \%$ \\
$(2005)$ & & $31.0 \%$ \\
\hline London (2005) & 19 & $35.2 \%$ \\
Area 1 & 128 & $20.3 \%$ \\
Area 2 & $171-336$ & $10.3 \%$ \\
Area 3 & & \\
\hline
\end{tabular}

${ }^{2}$ Taken from ONS indices of deprivation - ranked from 1 (most deprived), to 354 (least deprived)

http://www.communities.gov.uk/communities/neighbourhoodrenewal/deprivation/deprivatio $\underline{\mathrm{n} 07 /}$

${ }^{3}$ Derived from ONS population estimates for mid-2007:

http://www.statistics.gov.uk/statbase/product.asp?vlnk=14238 
Table 2. Coping constructs assessed by each item

\begin{tabular}{lll}
\hline & PCDC item & Underlying coping construct being assessed \\
\hline 1 & I can usually do something to make the situation better & Cognitive appraisal including feelings of efficacy and control \\
2 & I can see the good side of things & Positive reappraisal \\
3 & I find it hard to stop thinking about it & Rumination and preoccupation \\
4 & I can change how I feel & Emotion regulation \\
5 & I stay upset for several days & Perseveration of negative emotion \\
6 & Getting angry helps me to feel better & Proneness to responding with anger \\
7 & I try not to think about it & Denial and cognitive avoidance \\
8 & There is nothing I can do about it & Behavioural (dis)engagement and catastrophizing \\
9 & I can calm myself down & Self-soothing and the ability to manage negative emotions \\
10 & I try to think about how I can solve the problem & Active and constructive coping \\
11 & Sometimes I don't know why I'm upset & Emotional awareness \\
\hline
\end{tabular}


Table 3. Analysis of Covariance Summary - relationship between coping dimensions and anxiety controlling for age and gender

\begin{tabular}{|c|c|c|c|c|c|c|c|}
\hline Source & $S C A S$ & cores & $\begin{array}{l}\text { Sum of } \\
\text { Squares }\end{array}$ & $d f$ & $\begin{array}{l}\text { Mean } \\
\text { Square }\end{array}$ & $F$ & $\begin{array}{l}\text { Partial Eta } \\
\text { Squared }\end{array}$ \\
\hline Coping dimension & Yes & No & & & & & \\
\hline $\begin{array}{l}\text { Copes 1: I can usually do something to make the situation } \\
\text { better }\end{array}$ & 29.3 & 34.0 & 10008.73 & 1 & 10008.73 & $51.80 * * *$ & .09 \\
\hline Copes 1 x Year & & & 378.38 & 1 & 378.38 & 1.16 & .00 \\
\hline Copes 1 x Sex & & & 2259.35 & 1 & 2259.35 & $6.94 *$ & .00 \\
\hline Error & & & 828473.84 & 2546 & 325.40 & & \\
\hline Copes2: I can see the good side of things & 29.0 & 35.0 & 12102.16 & 1 & 12102.16 & $37.44 * * *$ & .01 \\
\hline Copes 2 x Year & & & 1137.39 & 1 & 1137.39 & $3.52 \dagger$ & .00 \\
\hline Copes 2 x Sex & & & 3657.13 & 1 & 3657.13 & $11.31 * * *$ & .00 \\
\hline Error & & & 822996.19 & 2546 & 323.25 & & \\
\hline Copes3: I find it hard to stop thinking about it & 35.4 & 22.9 & 79327.00 & 1 & 79327.00 & $265.14 * * *$ & .09 \\
\hline Copes 3 x Year & & & 2.77 & 1 & 2.77 & .01 & .00 \\
\hline Copes 3 x Sex & & & 172.89 & 1 & 172.89 & .58 & .00 \\
\hline Error & & & 761436.00 & 2545 & 299.19 & & \\
\hline Copes4: I can change how I feel & 28.2 & 34.9 & 23756.21 & 1 & 23756.21 & $74.16^{* * *}$ & .03 \\
\hline Copes 4 x Year & & & 543.07 & 1 & 543.07 & 1.70 & .00 \\
\hline Copes 4 x Sex & & & 804.65 & 1 & 804.65 & 2.51 & .00 \\
\hline Error & & & 815264.80 & 2545 & 320.34 & & \\
\hline Copes5 I stay upset for several days & 41.6 & 27.0 & 75552.57 & 1 & 75552.57 & $254.66 * * *$ & .09 \\
\hline Copes 5 x Year & & & 678.31 & 1 & 678.31 & 2.29 & .00 \\
\hline Copes 5 x Sex & & & 2922.73 & 1 & 2922.73 & $9.85^{*}$ & .00 \\
\hline Error & & & 755657.73 & 2547 & 296.69 & & \\
\hline Copes6 Getting angry helps me to feel better & 33.2 & 29.5 & 7842.50 & 1 & 7842.50 & $23.96 * * *$ & .01 \\
\hline Copes6 x Year & & & 22.66 & 1 & 22.66 & .07 & .00 \\
\hline
\end{tabular}




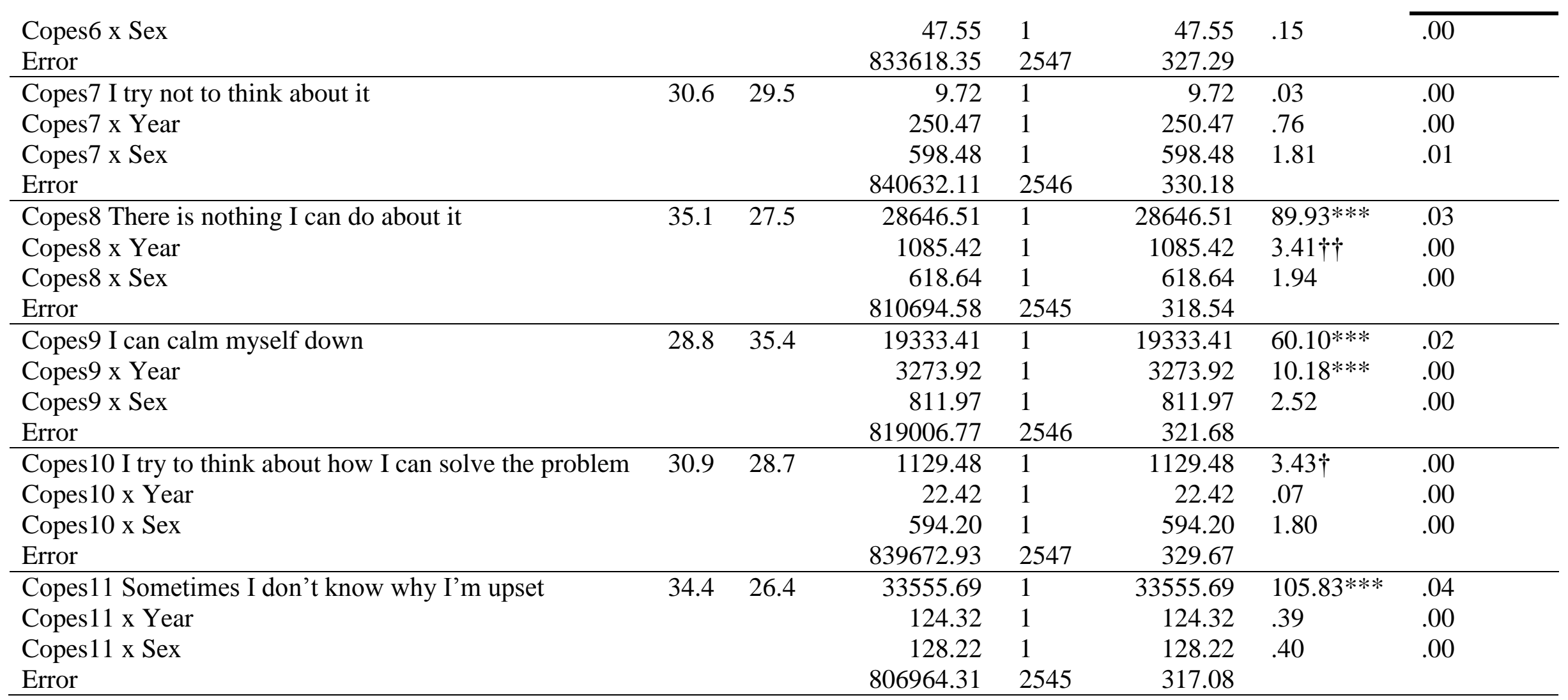

$* * * \mathrm{p}<0.001$

$* p<0.01$

$\dagger p=.06$

$\uparrow+p=.07$ 
Table 4. Adaptive and Maladaptive coping styles

\begin{tabular}{l|l}
\hline Adaptive coping & Maladaptive coping \\
\hline I can usually do something to make the & I find it hard to stop thinking about it \\
situation better & $\begin{array}{l}\text { There is nothing I can do about it } \\
\text { Sometimes I don't know why I'm upset } \\
\text { I try to think about how I can solve the } \\
\text { problem }\end{array}$ \\
$\begin{array}{l}\text { I can see the good side of things } \\
\text { I can change how I feel }\end{array}$ & \\
$\begin{array}{l}\text { I can calm myself down } \\
\text { I try not to think about it }\end{array}$ & \\
\hline
\end{tabular}

Table 5. Distribution of coping styles

\begin{tabular}{llccccc}
\hline Style & \multicolumn{2}{c}{ Total } & \multicolumn{2}{c}{ Girls } & \multicolumn{2}{c}{ Boys } \\
\hline Adaptive & 776 & $30.4 \%$ & 348 & $27.5 \%$ & 428 & $33.2 \%$ \\
Maladaptive & 662 & $25.9 \%$ & 398 & $31.4 \%$ & 264 & $20.5 \%$ \\
Versatile & 768 & $30.0 \%$ & 411 & $32.4 \%$ & 357 & $27.7 \%$ \\
Non-responsive & 350 & $13.7 \%$ & 110 & $8.7 \%$ & 240 & $18.6 \%$ \\
\hline & 2556 & & 1267 & & 1289 & \\
\hline
\end{tabular}


Table 6. Analysis of Covariance Summary - relationship between maladaptive and adaptive coping style and anxiety controlling for age and gender

\begin{tabular}{lrrrrr}
\hline Source & Sum of Squares & $d f$ & $\begin{array}{l}\text { Mean } \\
\text { Square }\end{array}$ & $F$ & $\begin{array}{l}\text { Partial } \\
\text { Eta } \\
\text { Squared }\end{array}$ \\
\hline Coping style & & & & & \\
\hline Adaptive & & & & & \\
Maladaptive & 3740.79 & 1 & 3740.79 & $13.06 * * *$ & .01 \\
Sex & 91554.58 & 1 & 91554.58 & $319.69^{* * *}$ & .11 \\
Year & 25667.08 & 1 & 25667.08 & $89.63^{* * *}$ & .03 \\
Adaptive x Maladaptive & 16399.73 & 1 & 16399.73 & $57.27 * * *$ & .02 \\
Adaptive x Sex & 5242.42 & 1 & 5242.42 & $18.31^{* * *}$ & .01 \\
Adaptive x Year & 4.08 & 1 & 4.08 & 0.01 & \\
Maladaptive x Sex & 346.08 & 1 & 346.08 & 1.21 & \\
Maladaptive x Year & 1711.84 & 1 & 1711.84 & $5.98^{*}$ & .00 \\
Error & 608.88 & 1 & 608.88 & 2.13 & \\
\hline
\end{tabular}

$* * * \mathrm{p}<0.001$

$* \mathrm{p}<0.05$ 
Figure 1. Estimated marginal means for anxiety for each coping style

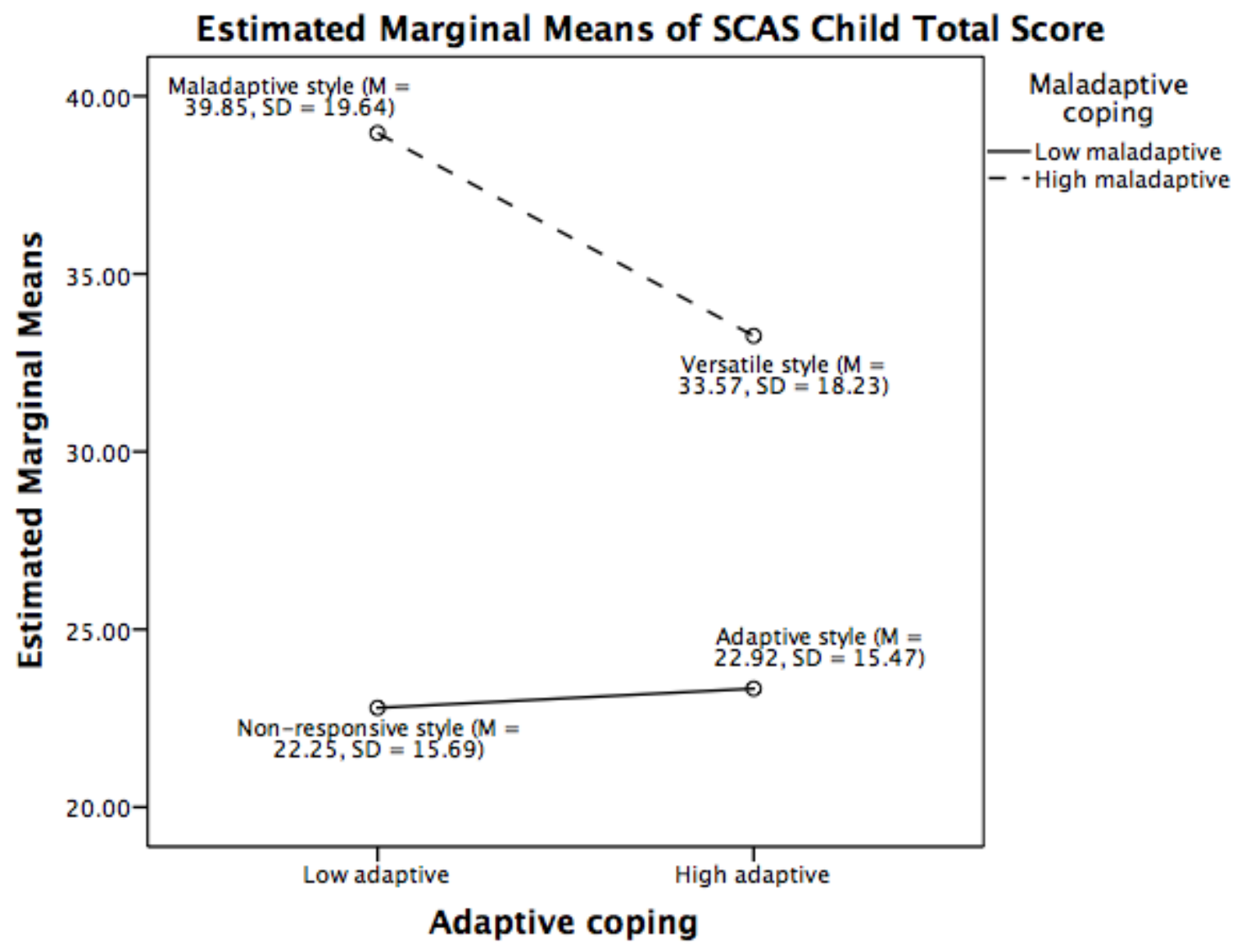




\section{References}

Ayers, T. S., Sandler, I. N., West, S. G., \& Roosa, M. W. (1996). A dispositional and situational assessment of children's coping: Testing alternative models of coping. Journal of Personality, 64(4), 923-958.

Barrett, P. M., Farrell, L. J., Ollendick, T. H., \& Dadds, M. (2006). Long-Term Outcomes of an Australian Universal Prevention Trial of Anxiety and Depression Symptoms in Children and Youth: An Evaluation of the Friends Program. Journal of clinical child and adolescent psychology, 35(3), 403-411.

Barrett, P. M., Lock, S., \& Farrell, L. J. (2005). Developmental Differences in Universal Preventive Intervention for Child Anxiety. Clinical Child Psychology and Psychiatry, 10(4), 539-555. doi:10.1177/1359104505056317

Barrett, P. M., \& Turner, C. M. (2001). Prevention of anxiety symptoms in primary school children: preliminary results from a universal school-based trial. British journal of clinical psychology 40(4), 399-410.

Bartlett, M. S. (1954). A note on the multiplying factors for various chi square approximations. Journal of the Royal Statistical Society, 16, 296-298.

Belzer, K. D., D’Zurilla, T. J., \& Maydeu-Olivares, A. (2002). Social problem solving and trait anxiety as predictors of worry in a college student population. Personality and Individual Differences, 33(4), 573-585. doi:http://dx.doi.org/10.1016/S0191-8869(01)00173-8

Cattell, R. B. (1966). The scree test for the number of factors. Multivariate Behavioral Research, 1(245), 276.

Chang, W., Cheng, J., Allaire, J. J., Xie, Y., \& McPherson, J. (2016). shiny: Web Application Framework for R. R package version 0.14.2. Retrieved from https://CRAN.R-project.org/package=shiny

Chavira, D. A., Stein, M. B., Bailey, K., \& Stein, M. T. (2004). Child anxiety in primary care: prevalent but untreated. Depression and anxiety, 20(4), 155-164.

Cisler, J. M., Olatunji, B. O., Feldner, M. T., \& Forsyth, J. P. (2010). Emotion Regulation and the Anxiety Disorders: An Integrative Review. Journal of Psychopathology and Behavioral Assessment, 32(1), 68-82. doi:http://doi.org/10.1007/s10862-009-9161-1

Cohen, J. (1960). A coefficient of agreement for nominal scales. Educational and Psychological Measurement, 20(1), 37-46.

Cohen, P., Cohen, J., Kasen, S., Velez, C. N., Hartmark, C., Johnson, J., \& Streuning, E. L. (1993). An Epidemiological Study of Disorders in Late Childhood and Adolescence-I. Age- and Gender-Specific Prevalence. Journal of Child Psychology and Psychiatry, 34, 851-867.

Compas, B. E., Connor-Smith, J. K., Saltzman, H., Thomsen, A. H., \& Wadsworth, M. E. (2001). Coping With Stress During Childhood and Adolescence: Problems, Progress, and Potential in Theory and Research. Psychological Bulletin, 127(1), 87-127.

Creswell, C., Violato, M., Fairbanks, H., White, E., Parkinson, M., Abitabile, G., .. . Cooper, P. J. (2017). Clinical outcomes and cost-effectiveness of brief guided parent-delivered cognitive behavioural therapy and solution-focused brief therapy for treatment of childhood anxiety disorders: a randomised controlled trial. The Lancet Psychiatry, 4(7), 529-539. doi:https://doi.org/10.1016/S22150366(17)30149-9

D'Zurilla, T. J., \& Goldfried, M. R. (1971). Problem solving and behavior modification. Journal of Abnormal Psychology, 78, 107-126. 
D'Zurilla, T. J., \& Nezu, A. M. (1982). Social problem solving in adults. In P. C. Kendall (Ed.), Advances in cognitive-behavioral research and therapy (Vol. 1, pp. 201-274). New York: Academic Press.

D'Zurilla, T. J., \& Nezu, A. M. (1999). Problem-solving therapy: a social competence approach to clinical intervention (2nd ed.). New York: Springer.

Degnan, K. A., Almas, A. N., \& Fox, N. A. (2010). Temperament and the environment in the etiology of childhood anxiety. Journal of Child Psychology and Psychiatry, 51(4), 497-517.

Delgado, M. R., Nearing, K. I., LeDoux, J. E., \& Phelps, E. A. (2008). Neural circuitry underlying the regulation of conditioned fear and its relation to extinction. Neuron, 59, 829-838.

Derryberry, D., \& Rothbart, M. K. (1988). Arousal, affect, and attention as components of temperament. Journal of personality and Social Psychology, 55(6), 958-966.

Dunbar, J. P., McKee, L., Rakow, A., Watson, K. H., Forehand, R., \& Compas, B. E. (2013). Coping, Negative Cognitive Style and Depressive Symptoms in Children of Depressed Parents. Cognitive Therapy and Research, 37(1), 18-28. doi:10.1007/s10608-012-9437-8

Eisenberg, N., Fabes, R. A., Karbon, M., Murphy, B. C., Wosinski, M., Polazzi, L., . . . Juhnke, C. (1996). The Relations of Children's Dispositional Prosocial Behavior to Emotionality, Regulation, and Social Functioning. Child Development, 67(3), 974-992.

Frydenberg, E., Lewis, R., Bugalski, K., Cotta, A., McCarthy, C., Luscombe-smith, N., \& Poole, C. (2004). Prevention is better than cure: coping skills training for adolescents at school. Educational Psychology in Practice, 20(2), 117-134. doi:10.1080/02667360410001691053

Garnefski, N., Legerstee, J., Kraaij, V., Van den Kommer, T., \& Teerds, J. (2002). Cognitive coping strategies and symptoms of depression and anxiety: A comparison between adolescents and adults. Journal of Adolescence (25), 603611.

Garnefski, N., Rieffe, C., Jellesma, F., Terwogt, M., \& Kraaij, V. (2007). Cognitive emotion regulation strategies and emotional problems in 9-11-year-old children. European child \& adolescent psychiatry, 16(1), 1-9.

Garnefski, N., Teerds, J., Kraaij, V., Legerstee, J., \& van den Kommer, T. (2004). Cognitive emotion regulation strategies and depressive symptoms: Differences between males and females. Personality and Individual Differences, 36, 267276.

Gilleland, J., Suveg, C., Jacob, M. L., \& Thomassin, K. (2009). Understanding the Medically Unexplained: Emotional and Familial Influences on Children's Somatic Functioning. Child: Care, Health and Development, 35(3), 383-390.

Gross, J. J. (1998). The emerging field of emotion regulation: An integrative review. Review of General Psychology, 2, 271-299.

Horn, J. L. (1965). A Rationale and Test For the Number of Factors in Factor Analysis. Psychometrika, 30, 179/185.

Kaiser, H. (1970). A second generation Little Jiffy. Psychometrika, 35, 401-415.

Kaiser, H. (1974). An index of factorial simplicity. Psychometrika, 39, 31-36.

Kaminsky, L., Robertson, M., \& Dewey, D. (2006). Psychological Correlates of Depression in Children with Recurrent Abdominal Pain. Journal of Pediatric Psychology, 31(9), 956. 
Kelly, M. M., Tyrka, A. R., Price, L. H., \& Carpenter, L. L. (2008). Sex differences in the use of coping strategies: predictors of anxiety and depressive symptoms. Depress Anxiety, 25(10), 839-846. doi:10.1002/da.20341

Kovacs, M. (1981). Rating scales to assess depression in school-aged children. Acta Paedopsychiatrica, 46, 305-315.

Ladouceur, R., Dugas, M. J., Freeston, M. H., Rhéaume, J., Blais, F., Boisvert, J., . . . Thibodeau, N. (1999). Specificity of generalized anxiety disorder symptoms and processes. Behavior Therapy, 30, 191-207.

Lyubomirsky, S., \& Nolen-Hoeksema, S. (1995). Effects of self-focused rumination on negative thinking and interpersonal problem solving. Journal of personality and Social Psychology, 69(1), 176-190.

McLean, C. P., \& Anderson, E. R. (2009). Brave men and timid women? A review of the gender differences in fear and anxiety. Clinical Psychology Review, 29(6), 496-505. doi:http://dx.doi.org/10.1016/j.cpr.2009.05.003

McRae, K., Gross, J. J., Weber, J., Robertson, E. R., Sokol-Hessner, P., Ray, R. D., . . Ochsner, K. N. (2012). The development of emotion regulation: an fMRI study of cognitive reappraisal in children, adolescents and young adults. . Social Cognitive and Affective Neuroscience, 7(1), 11-12.

Meltzer, H., Gatward, R., Goodman, R., \& Ford, R. (2004). The mental health of children and adolescents in Great Britain. Retrieved from London:

Nolen-Hoeksema, S., \& Girgus, J. S. (1994). The emergence of gender differences in depression in adolescence. Psychological Bulletin(115), 424-443.

Olejnik, S. F., \& Algina, J. (1984). A Review of Nonparametric Alternatives to Analysis of Covariance. Paper presented at the Annual Meeting of the American Educational Research Association.

Quy, K., Gibb, J., Neil, L., \& Smith, M. (in preparation). Development and preliminary validation of a self-report coping response measure in a community sample of children aged 7-11 years

Rieffe, C., Oosterveld, P., Miers, A. C., Meerum Terwogt, M., \& Ly, V. (2008). Emotion awareness and internalising symptoms in children and adolescents: The Emotion Awareness Questionnaire revised. Personality and Individual Differences, 45(8), 756-761.

Segerstrom, S. C., Tsao, J. C. I., Alden, L. E., \& Craske, M. G. (2000). Worry and Rumination: Repetitive Thought as a Concomitant and Predictor of Negative Mood. Cognitive Therapy and Research, 24(6), 671-688. doi:10.1023/a:1005587311498

Skinner, E., Pitzer, J., \& Steele, J. (2013). Coping as Part of Motivational Resilience in School: A Multidimensional Measure of Families, Allocations, and Profiles of Academic Coping. Educational and Psychological Measurement, 73(5), 803835.

Spence, S. H. (1998). A measure of anxiety symptoms among children. Behaviour Research and Therapy, 36(5), 545-566.

Spence, S. H., Barrett, P. M., \& Turner, C. M. (2003). Psychometric properties of the Spence Children's Anxiety Scale with young adolescents. Journal of Anxiety Disorders, 17(6), 605-625. doi:10.1016/s0887-6185(02)00236-0

Thomsen, A. H., Compas, B. E., Colletti, R. B., Stanger, C., Boyer, M. C., \& Konik, B. S. (2002). Parent Reports of Coping and Stress Responses in Children With Recurrent Abdominal Pain. Journal of Pediatric Psychology, 27, 215-226.

Thurstone, L. L. (1947). Multiple factor analysis: A development and expansion of vectors of the mind. Chicago: University of Chicago Press. 
Walker, L. S., Smith, C. A., Garber, J., \& Van Slyke, D. A. (1997). Development and validation of the Pain Response Inventory for children. Psychological assessment, 9(4), 392-405.

Wright, M., Banerjee, R., Hoek, W., Rieffe, C., \& Novin, S. (2010). Depression and Social Anxiety in Children: Differential Links with Coping Strategies. Journal of abnormal child psychology, 38(3), 405-419.

Zeidner, M., \& Endler, N. S. (1996). Handbook of Coping: Theory, Research, Applications. New York: Wiley.

Zimmer-Gembeck, M. J., \& Skinner, E. A. (2011). Review: The development of coping across childhood and adolescence: An integrative review and critique of research. International Journal of Behavioral Development, 35(1), 1-17. doi:10.1177/0165025410384923

Zimmermann, P., \& Iwanski, A. (2014). Emotion regulation from early adolescence to emerging adulthood and middle adulthood. International Journal of Behavioral Development, 38(2), 182-194. doi:doi:10.1177/0165025413515405 